\title{
The Demand and Need for Transparency and Disclosure in Corporate Governance
}

\author{
Benjamin Fung \\ Department of Business Administration, Caritas Institute of Higher Education, Hong Kong, China \\ *Corresponding Author: bfung2012@gmail.com
}

Copyright @ 2014 Horizon Research Publishing All rights reserved.

\begin{abstract}
Transparency and disclosure (T\&D) are essential elements of a robust corporate governance framework as they provide the base for informed decision making by shareholders, stakeholders and potential investors in relation to capital allocation, corporate transactions and financial performance monitoring. The importance of transparency has been widely recognized by both academics and market regulators, resulting in numerous rules and regulations being introduced over time to ensure timely and reliable disclosure of financial information, creating standards to which companies must adhere. Today, transparency is taking on a new meaning of more comprehensive and proactive disclosures instead of the release of corporate governance details or policies in a 'reactive' fashion. The new concept of transparency putting more responsibilities on the corporation not only let the truth be available to the public but imposes to disclose it to every stakeholder and different stakeholder groups. Corporate governance in today's global environment has become more complex and dynamic in recent years due to increased regulatory requirements and greater scrutiny, creating increased responsibilities for board of directors to comply with rigorous governance standards and also to cope with increasing demand from shareholders and other stakeholders for T\&D. Considerable attention has been focused on the corporate disclosure requirements and transparency since the Asian financial crisis. It has generally been agreed that the main failure leading to the financial crisis stemmed directly from the lack of financial disclosure and inadequate governance practices. Thus, corporations are now under pressure to provide timely, consistent and accurate information to shareholders and the public regarding financial performance, liabilities, control and ownership, and corporate governance issues. This is critical if investors are to be able to make informed judgments on the risks and rewards of any investment. On the other hand, the greater the extent of T\&D, the greater the level of confidence in the operation of markets, and the greater is the access to capital financing. Due to the growing awareness of investors' rights, corporations should focus their efforts to elevate their T\&D and overall level of corporate governance standards for the benefits of all their stakeholders.
\end{abstract}

Keywords Corporate Governance, Financial Reporting, Transparency and Disclosure

\section{Introduction}

Corporate governance has been seen at the forefront of establishing standards of corporate ethics aimed at reducing unscrupulous corporate practices while preserving a fair business environment. Corporate governance is also increasingly being considered an important part of enterprise risk management and the rationale is poor corporate governance is viewed as risky, whereas creditors and investors view good corporate governance (GCG) as a sign of strength in a corporation. The strength of a corporation's governance systems and the quality of its public disclosures are becoming increasingly important because stakeholders are paying more attention to what is reported and how. Thus, stakeholders are demanding better financial reporting and corporate transparency as well as more GCG practices through their management and board processes in order to lower their uncertainty towards investment decisions. It is widely believed, especially among investors, that GCG brings about better management and more prudent resource allocation and enhances better corporate performance. According to a McKinsey study (2002), over $60 \%$ of investors cite GCG practices in a corporation as a key factor in their investment decisions.

\section{Corporate Governance Framework}

Corporate governance is about the exercise of power over corporate entities. The board is the major driving force of governance in a company and primarily determines whether a company's governance is sound. The primary objective of GCG is to contribute to improved corporate performance. In any establishment, GCG starts with the owners and percolates down through the board and different management levels to the employees. No matter what the 
ownership is, there is a need for transparency and accountability in its relationship with other stakeholders. In this context, all rules that define the governance responsibilities, incentives and sanctions facing the board, management and staff must be well articulated. Board members must be held accountable and liable for their decisions and actions that have impact on the interests of other stakeholders. The basic principles of corporate governance are threefold:

The importance of transparency has been widely recognized by both academics and market regulators, resulting in numerous rules and regulations being introduced over time to ensure timely and reliable disclosure of financial information, creating standards to which companies must adhere. Corporate governance in today's global environment has become more complex and dynamic in recent years due to increased regulatory requirements and greater scrutiny, creating increased responsibilities for board of directors to comply with rigorous governance standards and also coping with increasing demand for T\&D. Considerable attention has been focused on the corporate T\&D since the Asian financial crisis. It has generally been agreed that the main failure leading to the financial crisis stemmed directly from the lack of financial disclosure and inadequate governance practices such as the supervision and accountability of directors. As a result, there has also been an increase in the number and complexity of accounting standards and other regulatory requirements for disclosure around the world to protect the investing public. Thus, corporations must provide adequate, accurate, and timely information to shareholders and the public regarding financial performance, liabilities, ownership, and corporate governance issues. This is critical if investors are to be able to make informed judgments on the risks and rewards of any investment (OECD, 1998). Beeks and Brown (2006) found out that companies with better governance also disclose more information. Those companies which are weak in governance are lacking of financial disclosure and transparency.

1. Transparency;

2. Accountability; and

3. Corporate control.

A corporate governance framework is provided in Figure 1 to explain GCG in a corporation.

Corporate governance concerns the control of a corporation, vested in the board of directors who play a crucial coordinating role to balance the interests of various stakeholders (both internal and external) and achieve sustainable profits. In general, corporate governance highlights the important principles of oversight and control over the executive management's performance and strategic directions; and their accountability to the shareholders. A code of ethics, which clarifies and stipulates adherence to some of more abstract ideals of trust and accountability, is essential for GCG. The board and management should endeavor to uphold and nurture accountability, transparency, fairness, and integrity in all aspects of the company operations.

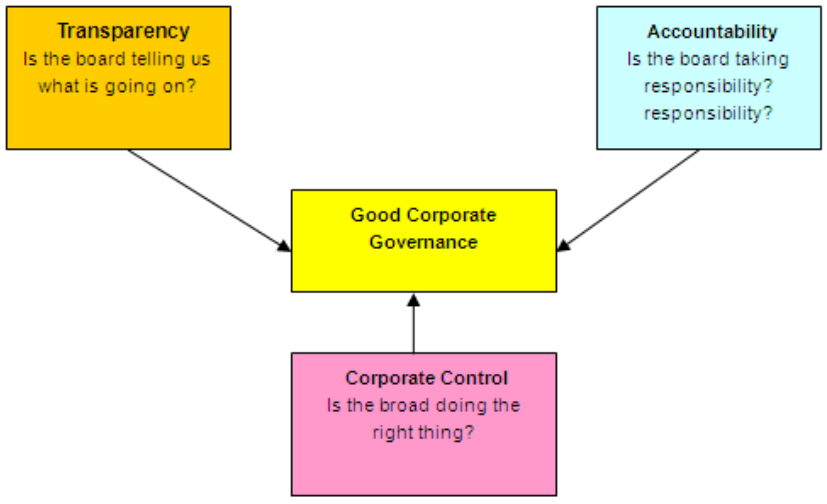

Figure 1. Corporate Governance Framework

Corporate transparency describes the extent to which a corporation's actions are observable by outsiders. Transparency is one of the key steps to corporate governance and ensures that management will not engage in improper or unlawful behavior since their conduct can be and will be scrutinized. To achieve transparency, a company should adopt accurate accounting methods, make full and prompt disclosure of company information and make disclosure of conflict of interests of the directors or controlling shareholders, etc. A key element of 'good' governance is 'transparency', which incorporates a system of checks and balances among the board of directors, management, auditors and other stakeholders. According to the principles of corporate governance of the Sarbanes-Oxley Act, 2002, organizations should clarify and make publicly known the roles and responsibilities of board and management to provide stakeholders with a level of accountability. Accountability ensures that managers utilize the company's resources in the most efficient and desirable manner as well as for the most appropriate goals without improper regard for personal interests. The UK Cadbury report stresses that making the accountability work is the responsibility of both the board and management. Management is accountable to the board, which in turn is accountable to shareholders. They should also implement procedures to independently verify and safeguard the integrity of the company's financial reporting and provide the quality of information to all stakeholders of the company. Disclosure of material matters concerning the organization should be timely and balanced to ensure that all investors have access to clear, factual information. All in all, T\&D enhance the control and behavior that support effective accountability for performance outcomes. An entity is more likely to achieve better result when corporate governance practices of $T \& D$ are given prominence within the organization. Conversely, firms with poor corporate governance strategies are more likely to underperform in the long term.

\section{Literature Review}

The OECD has the following working definition of 
corporate governance:

"Corporate governance is the system by which business corporations are directed and controlled. The corporate governance structure specifies the distribution of rights and responsibilities among different participants in the corporation, such as the board, managers, shareholders, and other stakeholders, and spells out the rules and procedures for making decisions on corporate affairs. By doing this, it also provides the structure through which the company objectives are set, and the means of attaining those objectives and monitoring performance.” This is summed up in a quote from Bosch Committee's statement (1995): “The essence of any system of good corporate governance is to allow the board and management the freedom to drive their organization forward but to exercise that freedom within a framework of effective accountability."

The term corporate governance refers to the systems and processes adopted to direct and manage the business and operation of a company. Corporate governance is defined by various authorities in different countries, and there are many different groups which have an interest in corporate governance. Different stakeholders' groups focus on different aspects in deciding what comprises GCG from their viewpoint. Shareholders, for example, are most likely to attach the greatest importance to those aspects which can maximize the market value of a corporation. Regulators are more focused on policy, compliance, supervision and operational issues. Employees look to the company for continued employment opportunities, and other groups have an interest in various social and environmental issues.

Regardless of which definition is preferred, any definition of corporate governance should encompass fundamental values of transparency, accountability, fairness and responsibility. ACCA (2009) defines three main purposes of corporate governance, which are:

- to ensure the board, as representatives of the organization's owners, protects resources and allocate them to make planned progress towards the organization's defined purposes;

- to ensure those governing and managing an organization account appropriately to its stakeholders; and

- to ensure shareholders and, where appropriate, other stakeholders, can and do hold boards to account.

Inherent in all three purposes is the requirements to transparently disclose the corporate governance structure, processes and issues faced by the company. In the governance and financial literature, transparency is related to the continuous dissemination through accessibility to media, consistent communication with stakeholders and periodic disclosure of firm-specific information on a voluntary or mandatory basis (Bushman, Piotroski and Smith, 2004; Yadong, 2005; Patel, 2002; and Pope, 2003). Such disclosure and dissemination can have a positive efficiency effect on obtaining capital (Uren, 2003) or enhance the firm's reputation (Bennis, Goleman and O’Toole, 2008; Fombrun, 1990, 1996, 2000).
GCG is a mandatory requirement in today's complex and dynamic business environment to ensure equity and transparency to every stakeholder and enhance the required values to different stakeholder groups. Corporations that demonstrate a commitment to high standards of corporate governance will benefit from the availability and lower cost of capital; improved competitiveness and financial performance; and truly sustainable long-term growth. The proliferation of scandals and crises arising from poor corporate governance strengthen strong demand of GCG to ensure long-term sustainability of corporations. So, GCG should be cultivated and practiced regularly within the current structure of the business.

\section{Transparency in Financial Reporting}

Financial reporting is a critical information component for investors in their decision making. Major risk in corporate financial reporting is that financial statements are not fairly presented due to inadvertent or intentional errors. Management may fail to provide certain information to many diverse users of financial statements, deliberately misleading them about the company's operations. Without the required information, it is impossible to fully understand a company's financial condition.

Transparency in financial reporting enables investors, creditors, and market participants to evaluate the financial condition of an entity. In addition to helping investors make better decisions, transparency increases confidence in the fairness of the markets. Thus, regulators should aim to ensure that markets are fair, efficient and transparent and investors are given fair access to market, price or corporate information. A complex and opaque financial report gives no idea about the genuine risks involved and the real fundamentals of the company. Companies with inscrutable financials and complex business structures are riskier and less valuable investments. There are some companies taking advantage of accounting rules in different ways that inhibit transparency. This may, for example, obscure the company's level of debt. If a company hides its debt, investors cannot estimate their exposure to bankruptcy risk. Moreover, transparency is important to corporate governance because it enables boards of directors to evaluate management's effectiveness and to take early corrective actions, when necessary, to address deterioration in the financial condition of companies. Therefore, it is critical that all public companies provide an understandable, comprehensive and reliable portrayal of their financial condition and performance. If the information in financial reports is transparent, then investors and other users of the information are less likely to be surprised by unknown transactions or events. Investors and creditors expect clear, reliable, consistent, comparable, and transparent reporting of events. Accounting standards provide a framework that is intended to present financial information in a way that facilitates informed judgments. For financial statements to 
provide the information that investors and other decision makers require, meaningful and consistent accounting standards and comparable practices are necessary. Good financial disclosure has become a corporate governance tool of forming expectations relating to future company performance.

Today, corporate reporting is no longer restricted to the financial statements, but encompasses a broad array of additional matters that must also be disclosed in order to give investors the critical information they need to value their investments. No longer focused on historic results, it now includes prospective elements, such as guidance on future revenue and earnings targets. Moreover, disclosure of a growing number of non-financial performance metrics is being required, together with an ever-increasing number of financial metrics. According to the publication of Guidance on Good Practices in Corporate Governance Disclosure by the United Nations Conference on Trade and Development 2006, the guidance places emphasis on financial disclosures and a range of non-financial disclosures such as company objectives; ownership and shareholders rights; changes in control and transactions involving significant assets; and governance structures and policies, etc.

Given the enormous volatility in the international capital markets, the demand and need for adequate transparency and suitable corporate financial reporting is essential. Corporate governance advocates would postulate sound corporate governance mechanisms are paramount in maintaining proper corporate financial reporting practices, thereby, aiding in easing tensions in international markets.

\section{Culture of Transparency}

Building a culture of transparency is a fundamental first step to achieving trust. Open and honest communications support the decision to trust. Lack of communication and transparency creates suspicion. Transparency happens only when an institution creates a culture of candor and respect, stakeholders feel free to speak the truth to the board and management. If the executives are willing to listen to opposing points of view and promise to consider the merits of others' arguments, they pave the way for a culture of transparency. Broadly defined, transparency refers to the degree to which information flows freely within an organization, among managers and employees, and outward to stakeholders. Bennis and O’Toole (2009) offer seven steps for developing a culture of transparency in the organization:

1. Tell the truth

2. Encourage people to speak truth to power

3. Reward contrarians

4. Practice having unpleasant conversations

5. Diversify information sources

6. Admit mistakes

7. Build organizational support for transparency

Many organizations today are genuinely committed to transparency, openness and candor. Transparency exists when information is assembled and made readily available to other parties and creates an informed and communicative environment conductive to greater cooperation among all parties in the organization. How effectively information flows through an organization is directly related to its culture? A board of directors of the organization bears direct responsibility for cultivating a culture of accountability and transparency. Truly independent boards must establish policies that ensure and reward transparency. They diligently monitor implementation, decisively intervene to ensure completeness, ensure that facts are not obscured and that conflicts of interest are eliminated. On the other hand, management's responsibility is to create the programs and processes to see that these policies are properly executed. In best practice organizations, top leaders are diligently committed to a culture of transparency. Not given to directives from the top or just mechanical processes of auditing, accountability permeates the organization and real commitments are made for collaboration and sharing information.

There is internal transparency and external transparency: users or customers - both difficult to achieve and both critical to success. Internal transparency puts the right information together with the right person at the right time. External transparency demonstrates communication of values to the company's customers and consumers.

\section{Corporate Governance and Disclosure}

Corporate governance is becoming an important investment assessment tool since there are ample empirical research findings showing a positive correlation between corporate governance and financial ratios, valuations and share-price performance. Increasingly, many investors look at corporate governance as one of the key elements when they make an investment decision. If investors take the view that poor corporate governance is a risk, it is absolutely necessary that companies need to improve their corporate governance standards in order to attract investment capital.

Nowadays, most countries are upgrading their laws and regulations to include compliance with GCG and T\&D standards and companies are voluntarily having their corporate governance and $T \& D$ practices rated, to signal their quality and to improve their current practices. There are five pillars of T\&D which comprise:

- Truthfulness - information disclosed must provide accurate description of circumstances.

- Completeness - information disclosed must be sufficient to enable investors to make informed decisions. Information must include both financial and non-financial matters.

- Materiality of information - information disclosed must be material to influence investment decisions.

- Timeliness - information disclosed must be timely to enable investors to react as quickly as possible. 
- Accessibility - information disclosed must be easily accessible and available to investors at low cost.

Disclosure of reliable, timely information contributes to liquid and efficient markets by enabling investors to make investment decisions based on all of the available information that would be material to their decisions. As a result, investors are demanding better reporting and greater transparency. They are demanding more information, and they are shouting louder than ever before.

Corporate governance systems are used by a company to promote fairness, complete and accurate financial reporting and accountability. T\&D are critical elements of a robust corporate governance framework as they provide the basis for informed decision making by shareholders, stakeholders and investors regarding capital allocation, corporate transactions, and financial performance monitoring. Hence, T\&D not only serves to investors but helps regulators in maintaining market confidence and system stability. T\&D are integral to corporate governance as higher transparency and better disclosure reduce the information asymmetry between a company's management and financial stakeholders, mitigating the agency problem in corporate governance. According to economic theory, reducing the information asymmetry by more voluntary financial disclosures on the stock market increases share liquidity and reduces equity cost of capital. In the agency view, risk-averse managers (agents) are expected to act opportunistically at the expense of the shareholders' and other stakeholders' (principals') interests. Since principal and agent have divergent interests and goals, agency problem may arise when agent makes decisions that result in the pursuit of goals that conflict with those of the principal. This raises the question of how the management can be made accountable and the process of governing the corporation more transparent.

Companies often make voluntary disclosures that go beyond minimum disclosure requirements in response to the market demand. A strong disclosure regime that promotes genuine transparency is pivotal for market-based monitoring of companies and central to shareholders' ability to exercise their ownership rights on an informed basis. Empirical experience in countries with large and active equity markets shows that disclosure can be a powerful tool for influencing the behavior of companies and protecting investors. A strong disclosure regime can help attract capital and maintain confidence in the capital markets. Conversely, weak disclosure and non-transparent practices can contribute to unethical behavior and a loss of market integrity at great cost, not just to the company and its shareholders, but also to the economy as a whole. Shareholders and potential investors require access to regular, reliable, and comparable information in sufficient detail for them to assess the stewardship of management and make informed decisions about the valuation, ownership and voting of shares. Insufficient or unclear information may hamper the ability of the markets to function, increase the cost of capital, and result in poor allocation of resources.
Corporate transparency is also important in case of multinational companies that operate through a network of related subsidiaries, affiliates, joint ventures and other holdings incorporated in diverse jurisdictions including some secrecy jurisdictions. Without transparency, many of these entities remain hidden from public view and scrutiny. Thus, it may be likely that material corporate holdings go unreported and investors do not have a clear and comprehensive picture of the Group's operations, revenues, profits and taxation. However, disclosure requirements are not expected to place unreasonable administrative or cost burdens on companies. Nor are companies expected to disclose information that may endanger their competitive position unless disclosure is necessary to enhance the investment decision and to avoid misleading the investors. In order to determine what information should be disclosed at a minimum, many countries apply the concept of materiality. Material information can be defined as information whose omission or misstatement could influence the economic decision taken by users of information.

\section{Transparency and Risk Management}

Transparency and strong corporate governance are needed in both domestic and international transactions and at all phases of investment. With the passage of the US Sarbanes Oxley Act of 2002, global companies have no choice but to push for good, transparent data availability. Rapid transparent data is becoming integral to the establishment of a "pipeline" of exposure and risk management information. Risk managers need consistent, accessible data on current and potential corporate exposures, the cost of managing risks now and in the past. This kind of information gives risk professionals the tools to price varying risk management alternatives.

There has already been much discussion about improving governance through the use of better internal financial controls. Risk managers could conceivably latch onto this as they seek to become more involved in enterprise risk management and the data needed to support that system. Fueled by closer scrutiny of corporate governance risk and the drive to increase shareholder value, data transparency has become good tool against risk exposure. The move towards greater financial transparency, the better governance and enhanced shareholder value can be achieved.

There is also an increasing demand on good governance since institutional investors gather bigger and more concentrated share proportions. Since investors' decisions more and more depend on governance metrics, management of listed companies face pressure to further upgrade their corporate governance standards and adopt international best practices of good governance. Accordingly, companies should keep an eye on reporting on corporate governance because GCG has to be recognizable at first to be an effective value driver in order to attract investment capital. Otherwise capital markets cannot work efficiently. 
Transparency lies at the intersection between the public's right to know and corporation's right to privacy. The public's right to know means the stakeholders' interest in obtaining corporation information about management and strategy. The stakeholders have a legitimate claim to know vast quantities of information about corporation's actions and intents. On the other hand, the corporation's right to privacy means the corporation's right to control the collection, use and disclosure of all information and management strategies in relation to the corporation. Opacity, the opposite of transparency, is defined as the state of being hard to understand and not clear or lucid. When information is not clear, it is not trusted. When information is hidden, it is natural to believe there is truly something to hide.

\section{Corporate Governance: Best Practice Reporting in Hong Kong}

Hong Kong is devoted to maintaining its prominent reputation as an international financial center. To continue delivering on its goal, Hong Kong listed companies need to maintain GCG practices as a top priority. GCG enhances the credibility and reputation of the company as well as promoting and safeguarding the interests of shareholders and other stakeholders. Moreover, investors are demanding better financial disclosure and greater transparency and also demanding more GCG practices.

The Hong Kong Stock Exchange's (HKEx’s) Corporate Governance Code and Corporate Governance Report contained in Appendix 14 of the Rules Governing the Listing of Securities on the Stock Exchange of Hong Kong Limited (the Listing Rules) sets out the principles of GCG and two levels of recommendation:

1. Code provisions, with which issuers are expected to comply or to give considered reasons for non-compliance ${ }^{1}$; and

2. Recommended best practices are for guidance only. Issuers may devise their own code on the terms they consider appropriate.

Since 2005, it has been mandatory for Hong Kong listed companies to include in their financial reports a Corporate Governance Report (CGR). CGR must contain all the information set out in Paragraphs G to P of Appendix 16. Any failure to do so will be regarded as a breach of the Listing Rules. The Listing Rules reflect currently acceptable standards in the market place and are designed to achieve a number of objectives to ensure that investors have and can maintain confidence in the market.

CGR provides a reliable account of a company's corporate governance practices. Benefits and values of CGR include

- Primary source of communication with shareholders

- Shareholders rely on the CGR to assess corporate governance performance

\footnotetext{
${ }^{1}$ This 'comply or explain' mechanism offers companies the flexibility to choose between complying with the provisions of the code, or explaining deviation in their CGR and enhances transparency and disclosure.
}

- Correct evaluation of company by outsider

- Reputation is at stake

- Help in the actual evaluation of corporate governance

In essence, the board of directors must confirm that the company has strictly complied with the Corporate Governance Code and CGR for the year under review and CGR must be included in the annual report and interim report.

A survey conducted by the Hong Kong Institute of Directors (HKIoD) and the Hong Kong Baptist University on the corporate governance practices of 121 listed companies in Hong Kong based on information disclosed in their 2011 annual reports, websites, and publicly available financial statements. The HKIoD Corporate Governance Score-card 2012 survey assessed the corporate governance performance of the 121 public companies listed on the Hong Kong Stock Exchange, which are components of four major Hong Kong stock indexes namely:

1. Hang Seng Index ${ }^{2}$ (HIS)

2. Hang Seng China-Affiliated Corporation Index (HSCCI)

3. Hang Seng China Enterprises Index (HSCEI)

4. Hang Seng Hong Kong Large Cap Index (HSLI)

The survey was based on the Principles of Corporate Governance promulgated by the Organization for Economic Cooperation and Development (OECD) and the HKEx's Corporate Governance Code and CGR. With a survey questionnaire of 151 questions, corporate governance practices were assessed across five important sections of OECD principles. Table 1 shows the number of questions in five sections of the questionnaire, plus the corresponding weighting for the section.

Table 1. Survey Question Weightings

\begin{tabular}{|c|c|c|}
\hline $\begin{array}{c}\text { OECD Principle and Survey } \\
\text { Section }\end{array}$ & $\begin{array}{c}\text { Number of Questions } \\
\text { and Sub-questions }\end{array}$ & $\begin{array}{c}\text { Section } \\
\text { Weighting }\end{array}$ \\
\hline Rights of shareholders & 23 & $15 \%$ \\
\hline $\begin{array}{c}\text { Equitable treatment of } \\
\text { shareholders }\end{array}$ & 14 & $10 \%$ \\
\hline Role of stakeholders & 13 & $20 \%$ \\
\hline Disclosure and transparency & 42 & $25 \%$ \\
\hline Board responsibilities & 59 & $30 \%$ \\
\hline Total & 151 & $100 \%$ \\
\hline
\end{tabular}

Table 2. presents the descriptive statistics for the overall survey results of the 2012 Hong Kong Corporate Governance Index (CGI).

${ }^{2}$ Hang Seng Indexes calculate and manage the Hang Seng Family of Indexes. Starting in 1969 with the creation of the Hang Seng Index, now widely recognized as the barometer of the Hong Kong stock market, Hang Seng Indexes have been at the forefront of the market, developing numerous market measures to help investors make their investment decisions. 
Table 2. Descriptive Statistics for Hong Kong CGI

\begin{tabular}{|c|c|}
\hline Minimum & 56.92 \\
\hline Mean & 71.91 \\
\hline Maximum & 87.59 \\
\hline Standard deviation & 7.75 \\
\hline Sample size & 121 \\
\hline
\end{tabular}

Table 2 shows the average corporate governance score or CGI for the 2012 survey was 71.91 on a scale of 0 to 100 . The scores ranged from a minimum of 56.92 to a maximum of 87.59 showing a larger amount of standard deviation.

Figure 2 shows the summary of the survey results of CGI scores based on the five OECD corporate governance principles as follows:

The average score of 87.61 in Section A is the most prominent among the five survey sections reflecting the concern that Hong Kong listed companies’ establishment of transparent mechanisms for securing the rights and interests of shareholders is a top priority of their corporate governance. Disclosure and transparency, the foundation of corporation governance, receive the second highest average score of 81.73 for Section D indicating companies employing good governance principles should try their best to ensure timely and accurate disclosure of all material matters regarding the corporation including the financial situation, performance, ownership, management structure and governance of the company. The average score of 52.71 in Section $C$ is the lowest of the five sections implying that many companies should put forth greater effort on their corporate social responsibility activities.

The survey was carried out with the objective to assist the policy makers of Hong Kong companies to identify ways to improve corporate governance practices. The recommended improvements in the best practice of corporate governance are shown in Table 3:

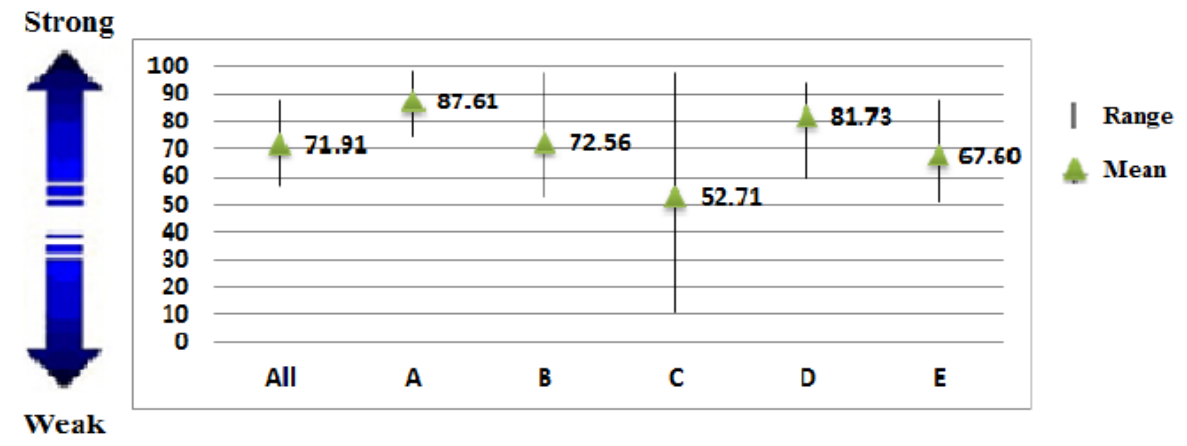

Legend:

A: Rights of shareholders;B: Equitable treatment of shareholders;

C: Role of stakeholders;D: Disclosure and transparency;E: Board responsibilities

Figure 2. CGI Scores By Survey Section

Table 3. Recommended improvements in the best practice of corporate governance

\begin{tabular}{|c|c|c|}
\hline & Range/ $\boldsymbol{\Delta}$ Mean & Improvements: \\
\hline A & $\underline{98.38 \Delta 87.6174 .53}$ & $\begin{array}{l}\text { - Provide the Annual General Meeting (AGM) } \\
\text { minutes } \\
\text { - } \quad \text { Board members attend the AGM } \\
\text { - Provide Question and Answer session }\end{array}$ \\
\hline B & $\underline{97.37 \Delta \mathbf{\Delta} 72.5652 .63}$ & $\begin{array}{l}\text { - Mechanism to allow minority shareholder } \\
\text { participation such as cumulative voting }\end{array}$ \\
\hline C & $\underline{97.27 \Delta \Delta 52.7110 .61}$ & $\begin{array}{ll}\text { - } & \text { Underprivileged workers } \\
\text { - } & \text { Corporate social responsibility report } \\
\text { - Explicitly mention environmental issues in its } \\
\text { public communications }\end{array}$ \\
\hline $\mathrm{D}$ & $\underline{93.47 \Delta 81.7359 .45}$ & $\begin{array}{ll}\text { - } & \text { Corporate governance structure } \\
\text { - } & \text { The information of the company secretary } \\
\text { - The disclosure of management's shareholdings }\end{array}$ \\
\hline $\mathrm{E}$ & $\underline{87.36 \Delta 67.6051 .10}$ & $\begin{array}{ll}\text { - } & \text { Corporate vision/mission } \\
\text { - } & \text { Professional/accredited directors' training } \\
\text { - } & \text { Orientation to new directors } \\
\text { Whistle-blowing policy }\end{array}$ \\
\hline
\end{tabular}

Source: Scorecard powerpoint presentation by HKIoD for press 2012 
One noticeable finding from the survey was that more than half of the top ten firms (like Bank of China, China Life, China COSCO, China National Offshore Oil, Industrial and Commercial Bank of China and Lenovo Group) with the best corporate governance practices are state-owned or backed with funding from China, reflecting that many large state-owned enterprises' management have devoted the time and resources needed to improve transparency, to clarify the power and responsibilities of the board of directors, and to enhance their firms' corporate social responsibility efforts. It may be that the pressure for GCG will come not from Hong Kong investors but from the overseas investors. Hong Kong remains an attractive place for Chinese enterprises to raise funds from, and for international investors to invest their money in, only if the corporate governance requirements of its stock exchange surpass those of China, which is increasingly adopting international standards. The best examples of corporate governance in Hong Kong remain equal to any in the other regions. It is not only the regulators who monitor the quality of Hong Kong listed companies' corporate governance disclosures. The Hong Kong Institute of Certified Public Accountants and professional service firm BDO Limited both conduct an annual corporate governance review, giving a snapshot of how corporate governance has progressed in Hong Kong listed companies.

Another compliance challenge came along on 1 January 2013 when amendments to the Securities and Futures Ordinance (SFO) of 2012 brought in Hong Kong's new regulatory regime for disclosure of inside information. The first hurdle companies have encountered in their compliance programs has been the tricky question of defining inside information. The information considered to be inside must be relevant (concern about the company, a shareholder or an officer of the company, or the listed securities or their derivatives); must not be widely known to the public; and, if known, must be likely to materially affect the company's share price. Not all inside information needs to be disclosed. To remedy, the information may be covered by one of the safe harbors outlined in the revised SFO, for instance, it concerns an incomplete proposal or negotiation or the information is a trade secret. If this is the case, the directors' compliance challenge will be to keep the information confidential than disclosing the information. The directors are also expected to be clear on what they can and cannot disclose. If the information is not covered by a safe harbor, it needs to be disclosed in a formal announcement as soon as reasonably practicable. Moreover, the boards have to determine whether it triggers a disclosure obligation under the SFO. The boards must debate and arrive at a consensus before making a disclosure. Thus, the directors may need to be advised of the company's obligations under Part XIVA of the SFO, the Securities and Futures Commission (SFC) Guidelines on Disclosure of Inside Information, the scope of their $\mathrm{D} \& \mathrm{O}$ (directors and officers) policies and other relevant information in a practical manner. A listed company, unless exempted by one of the safe harbors, must, as soon as reasonably practicable after any inside information has come to its knowledge, disclose that information to the public. From the company's perspective, the new inside information disclosure regime represents a major compliance challenge for both directors and company secretaries, the latter need to provide real input in helping to monitor and determine the disclosure decisions. For the companies, it can improve transparency and boost the effectiveness of internal controls needed to ensure that inside information is identified and escalated to the board and that confidential information can stay confidential.

\section{Conclusion}

Given the enormous volatility in the international capital markets which can give rise to uncertainty, the demand and need for adequate transparency, disclosure and suitable corporate financial reporting is essential to investors who can make better decisions on a more timely and informed basis. Escalating present capital market volatility is pushing for further demand on sound corporate governance practices and the demand for improved financial reporting and broader levels of transparency to lessen the fear and panic of investors. The stock exchanges around the world become increasingly conscious of their roles as self-regulatory institutions and explore the possibility of using the listing requirements as a tool for raising the standard of corporate governance. The issue of GCG is an imperative for ensuing successful corporate performance. A commitment to GCG in terms of well-defined shareholder rights, high levels of T\&D and responsible board of directors, etc. will make a company both attractive to investors and more chance to achieve good performance. The corporate governance principles emphasize an effective board, prudent internal control, transparency and accountability to its shareholders. A high standard of GCG practices and procedures are essential for effective management to enhancing shareholders' value. Building GCG is a shared responsibility among all stakeholders, each of whom may exert pressure to move forward a corporation.

In short, greater transparency in disclosures is essential for effective financial reporting and supervision. By adopting greater financial transparency, companies provide the necessary information for investors to monitor their governance process and behavior. Management needs to avoid excessive disclosures which could impair competitiveness. Increasing transparency will be important key to future success of corporate governance. Only with transparency will it be possible to defer frauds, embezzlement and financial scandals and foster efficiency in allocation of resources decisions. More importantly, T\&D allow firms to compete on the basis of their best offerings and to differentiate themselves from firms which do not practice good governance. 


\section{REFERENCES}

[1] Association of Chartered Certified Accountants (ACCA) (2009). Disclosures on Corporate Governance, Reporting Trilogy - Research on Reporting Disclosures: Part 2

[2] BDO Corporate Governance Review 2012, 7th Annual Review on HSCI Companies

[3] Beeks, W. and Brown, P. (2006). Do better-governed Australian firms make more informative disclosures? Journal of Business Finance and Accounting, Vol. 33/3-4, p. 422 450

[4] Bennis, W., Goleman, D., and O’Toole, J. (2008). Transparency: How leaders create a culture of candor, San Francisco, Jossey-Bass

[5] Bennis, W. and O’Toole, J. (2009). A Culture of Candor, Harvard Business Review

[6] Bhasin, M.L. (2010). Dharma, Corporate Governance and Transparency: An Overview of the Asian Markets, International Journal of Business and Management, Vol. 5/6, p. $56-73$

[7] Bosch Committee (1995). Corporate Practices and Conduct, 3rd edition, Australia

[8] Bushman, R., Piotroski, J., and Smith, A. (2004). What determines corporate transparency? Journal of Accounting Research, 42 (2), p. 207 - 252

[9] Bushman, R. and Smith, A. (2003). Transparency, Financial Accounting Information, and Corporate Governance, FRBNY Economic Policy Review, Vol. 9/1, p. 65 - 87

[10] Cheung, Y., Connelly, J., Limpaphayom, P. and Zhou, L. (2006). Determinants of Corporate Disclosure and Transparency: Evidence from Hong Kong and Thailand

[11] Code of Corporate Governance (Appendix 14, Hong Kong Stock Exchange Listing Rules, Jan 2012)

[12] Disclosure of Financial Information (Appendix 16, Hong Kong Stock Exchange Listing Rules, Jan 2012)

[13] Fombrum, C. and Shanley, M. (1990). What's in the Name? Reputation building and corporate strategy, Academy of Management Review, 33 (2), p. 233-258

[14] Fombrum, C. (1996). Reputation: Realizing value from the corporate image, Boston, MA, Harvard Business School Press

[15] Fombrum, C., Gardberg, N. and Barn, M. (2000). Opportunity platforms and safety nets: Corporate citizenship and reputational risk, Business and Society Review, 105 (1), p. $85-106$

[16] Goo, S. and Carver, A. (2003). Corporate Governance The Hong Kong Debate, Sweet \& Maxwell Asia

[17] Hong Kong Exchanges And Clearing Limited 2012 Annual Report

[18] Hong Kong Stock Exchange (HKEx) - Rules and Guidance on Listing Matters http://www.hkex.com.hk/eng/rulesreg/listrules/rulesandguide lines.htm

[19] International Standards of Accounting and Reporting
Guidance on Good Practices in Corporate Governance Disclosure

[20] KPMG (2005). The Hong Kong Code on Corporate Governance Practice ADVISORY

[21] McKinsey \& Company (2002). Global Investor Opinion Survey

[22] Organization for Economic Co-operation and Development (1998). Corporate Governance: Improving Competitiveness and Access to Capital in an Era of Global Markets. Report to OECD by the Business Sector Advisory Group on Corporate Governance

[23] Patel, S., Balic, A. and Bwakira, L. (2002). Measuring transparency and disclosure at firm-level in emerging markets, Emerging Markets Review, 3, p. 325 - 327

[24] Pope, P. (2003). Discussion of disclosure practices, enforcement of accounting standards and analysts' forecast accuracy: An international study, Journal of Accounting Research, 41(2), p. 273-283

[25] Report on HKIoD Corporate Governance Score-card 2012 and HKIoD Corporate Governance Project organized by the Hong Kong Institute of Directors and Hong Kong Baptist University

[26] Shil, N. (2008). Accounting for Good Corporate Governance, Journal of Administration \& Governance, Vol. 3/1

[27] Smerdon, R. (2013). A Practical Guide to Corporate Governance, 4th ed., Sweet \& Maxwell

[28] Smith, R. Role of Disclosure in Corporate Governance, US SEC Commission

[29] Stiglbauer, M. (2010). Transparency and disclosure on corporate governance as a key factor of companies' success: a simultaneous equations analysis of Germany, Section 3. General Issues in Management, Problems and Perspectives in Management, Vol. 1/8

[30] The Journal of the Hong Kong Institute of Chartered Secretaries, April 2010, January 2013, August 2013 and October 2013 issues

[31] The OECD (Organization for Economic Co-operation and Development) Principles of Corporate Governance (2004)

[32] The UNCTAD (United Nations Conference On Trade and Development) Guidance on Good Practices in Corporate Governance Disclosure (2006)

[33] Tricker, B. (2009). Corporate Governance Principles, Policies and Practices, Oxford University Press

[34] Uren, D. (2003). The transparent corporation: Managing demands for disclosure, Crow's Nest, NSW, Australia, Allen and Unwin

[35] Yadong, L. (2005). Corporate governance and accountability in multinational enterprises: Concepts and agenda, Journal of International Management, 11, p. 1-18 